\title{
What is the most cost-effective strategy for nasal screening and Staphylococcus aureus decolonization in patients undergoing total hip arthroplasty?
}

Hisahiro Tonotsuka ${ }^{1,2^{*}}$ (D) Hajime Sugiyama ${ }^{1,2}$, Ayano Amagami ${ }^{1,2}$, Keigo Yonemoto ${ }^{1,2}$, Ryuichi Sato ${ }^{1,2}$ and Mitsuru Saito ${ }^{2}$

\begin{abstract}
Background: To reduce periprosthetic joint infection after total hip arthroplasty (THA), several nasal screening and decolonization strategies for methicillin-resistant Staphylococcus aureus (MRSA) and methicillin-sensitive Staphylococcus aureus (MSSA) have been performed. These include universal decolonization (UD; i.e., no screening and decolonization for all patients), universal screening and target decolonization (US; i.e., screening for all patients and decolonization for bacterial positive patients), and target screening and decolonization (TS; i.e., screening and decolonization for high-risk populations only). Although TS is the most cost-effective strategy, useful risk factors must be identified. The purpose of this study was to evaluate the presence of predictive factors that enable the TS strategy to be successfully implemented and to compare the costs of each strategy.
\end{abstract}

Methods: A total of 1654 patients scheduled for primary or revision THA (1464 female, 190 male; mean age 64 years) were screened prior to surgery for bacterial colonization of the nasal mucosa. Risk factors for positive MRSA and S. aureus (including both MRSA and MSSA) tests were analyzed according to the following parameters: sex, age $\geq 80$ years, body mass index $\geq 30 \mathrm{~kg} / \mathrm{m}^{2}$, antibiotic use within 3 years, corticosteroid use, serum albumin $<3.5 \mathrm{~g} / \mathrm{dL}$, glomerular filtration rate $<50 \mathrm{~mL} / \mathrm{min}$, presence of brain, thyroid, cardiac, or pulmonary disease, diabetes, asthma, smoking status, and whether revision surgery was performed. The average cost of each strategy was calculated.

Results: In total, 29 patients (1.8\%) tested positive for MRSA and 445 (26.9\%) tested positive for S. aureus. No parameters were identified as independent risk factors for MRSA and only female sex was identified as a risk factor for $S$. aureus $(p=$ 0.003; odds ratio: 1.790; $95 \%$ confidence interval: 1.210-2.640). The average cost of each strategy was 1928.3 yen for UD, 717.6 yen for US, and 717.6 yen for TS (for eradicating MRSA), and 1928.3 yen for UD, 1201.6 yen for US, and 1160.4 yen for TS (for eradicating S. aureus).

Conclusions: No useful predictive parameters for implementing the TS strategy were identified. Based on cost implications, US is the most cost-effective strategy for THA patients.

Keywords: Total hip arthroplasty, Staphylococcus aureus, Periprosthetic joint infection, Nasal decolonization, Screening

\footnotetext{
* Correspondence: nqi37568@nifty.com

${ }^{1}$ Department of Orthopaedic Surgery, Kanagawa Rehabilitation Hospital, 516

Nanasawa, Kanagawa 516, 243-0121 Atsugi, Japan

${ }^{2}$ Department of Orthopaedic Surgery, The Jikei University School of

Medicine, 3-19-18 Nishishinbashi, Minato-ku 105-8471 Tokyo, Japan
}

C The Author(s). 2021 Open Access This article is licensed under a Creative Commons Attribution 4.0 International License, which permits use, sharing, adaptation, distribution and reproduction in any medium or format, as long as you give appropriate credit to the original author(s) and the source, provide a link to the Creative Commons licence, and indicate if changes were made. The images or other third party material in this article are included in the article's Creative Commons licence, unless indicated otherwise in a credit line to the material. If material is not included in the article's Creative Commons licence and your intended use is not permitted by statutory regulation or exceeds the permitted use, you will need to obtain permission directly from the copyright holder. To view a copy of this licence, visit http://creativecommons.org/licenses/by/4.0/. The Creative Commons Public Domain Dedication waiver (http://creativecommons.org/publicdomain/zero/1.0/) applies to the data made available in this article, unless otherwise stated in a credit line to the data. 


\section{Background}

Total hip arthroplasty (THA) is a common surgical procedure, and the number of such procedures performed is expected to increase with increasing aging of society [1]. Although THA is an effective procedure with a low complication rate, periprosthetic joint infection (PJI) following THA is a devastating complication. PJI from methicillin-resistant Staphylococcus aureus (MRSA) and methicillin-sensitive Staphylococcus aureus (MSSA) leads to increased mortality, longer hospitalization, and higher costs [2, 3]. Therefore, prevention and control strategies for PJI caused by MRSA and MSSA are critical for both patient safety and cost reduction.

One of the most important factors in reducing infections is identifying and eradicating nasal bacterial colonization prior to surgery. Previous studies have shown that preoperative nasal decolonization for $S$. aureus (including both MRSA and MSSA) in THA patients can reduce the risk of surgical site infection (SSI), which can lead to PJI $[4,5]$. However, various screening and decolonization strategies have been reported: universal decolonization (UD), which involves no screening and decolonization of all patients [6,7]; universal screening and target decolonization (US), which involves screening for all patients and decolonization for MRSA or S. aureus-positive patients [4, 5, 8, 9]; and target screening and decolonization (TS), which involves screening for highrisk populations only and decolonization for MRSA or $S$. aureus-positive patients [10]. Controversy remains as to the most appropriate strategy.

Although UD can significantly reduce the prevalence of $S$. aureus carriers without a waiting period for screening results [7], the protocol has problems of higher cost and the development of resistant strains [11]. US can reduce sampling error rates and offers a cost-effective screening method $[4,5]$. One option to reduce the cost of screening is to implement TS based on certain 'risk factors'. However, this strategy requires determining these risk factors with appropriate sensitivity and specificity. According to Dave et al., the TS method failed to detect half of the MRSA-positive cases in their study [8]. Thus, clarifying whether proper predetermined factors are correlated with the risk of $S$. aureus carrier status is important in TS. Moreover, although financial considerations are crucial for implementing nasal screening and decolonization, few reports have compared the relative costs of these three strategies after performing simulations and whether TS is actually able to reduce costs after searching for useful risk factors that allow this strategy to be implemented.

The purpose of this study was to investigate whether it is possible to determine the predictive factors for successful implementation of the TS strategy with $S$. aureus carriers, and to clarify the most cost-effective strategy for patients who undergo THA surgery.

\section{Methods}

We evaluated 1654 patients (1464 female, 190 male; mean age at time of surgery 64 (21-89) years) who underwent primary or revision THA from March 2008 to December 2017 at our institution. The study included 1499 cases of primary THA and 155 cases of revision THA.

All patients were screened for nasal bacterial colonization with a sterile swab 1-4 weeks prior to surgery. Patients who tested positive for MRSA or MSSA were registered. Patients positive for MRSA were treated with mupirocin for both nares twice for 5 days. The prevalence of S. aureus and MRSA carriers was investigated, and all patients were divided into two groups based on the presence of MRSA-MRSA-positive (MR+) group and MRSA-negative (MR-) group-and then based on the presence of $S$. aureus $-S$. aureus-positive $(\mathrm{SA}+)$ group and $S$. aureus-negative $(\mathrm{SA}-)$ group. Risk factors for positiveS. aureus and MRSA tests were analyzed according to the following parameters: sex, age at time of surgery ( $\geq 80$ or $<80$ years), body mass index (BMI: $\geq 30$ or $<30 \mathrm{~kg} / \mathrm{m}^{2}$ ), antibiotic use within 3 years before surgery, previous or present corticosteroid use, serum albumin $(<3.5$ or $\geq 3.5 \mathrm{~g} / \mathrm{dL})$, glomerular filtration rate (GFR: $<50$ or $\geq 50 \mathrm{~mL} / \mathrm{min}$ ), presence or not of brain, thyroid, cardiac, or pulmonary disease, diabetes, asthma, smoking habit, and whether revision surgery was performed. Screening and decolonization costs for each strategy were calculated. Based on average figures for our institution, a surgeon's hourly rate is 4666 yen, a medical assistant's hourly rate is 1722 yen, and a laboratory technician's hourly rate is 1758 yen. The time expenditure was as follows: selection of patients for screening using the TS strategy by the surgeon, $1 \mathrm{mi}-$ nute; assessment of the culture results by the surgeon, 1 minute; nasal swab sample obtained by a medical assistant, 1 minute; instructions on how to apply mupirocin ointment by a medical assistant, 10 minutes; and processing of each laboratory test by a laboratory technician, 5 minutes.

Fisher's exact test was used for univariate analysis to identify risk factors for S. aureus and MRSA, and stepwise logistic regression was used for multivariate analysis.

\section{Results}

\section{Number of cases for each parameter}

The study included 1464 female patients (88.5\%) and 190 male patients $(11.5 \%)$. The number of cases for each parameter was as follows: age $\geq 80$ years, 70 cases (4.2\%); BMI $\geq 30 \mathrm{~kg} / \mathrm{m}^{2}, 93$ cases $(5.6 \%)$; previous antibiotic use, 337 cases (20.4\%); corticosteroid use, 36 cases (2.2\%); serum albumin < $3.5 \mathrm{~g} / \mathrm{dL}, 18$ cases $(1.1 \%)$; GFR < $50 \mathrm{~mL} / \mathrm{min}, 108$ cases $(6.5 \%)$; brain disease, 54 cases 
(3.3\%); thyroid disease, 29 cases (1.8\%); cardiac disease, 21 cases (1.3\%); pulmonary disease, 20 cases (1.2\%); diabetes, 109 cases (6.6\%); asthma, 55 cases (3.3\%); smoking habit, 76 cases (4.6\%); and revision surgery, 155 cases $(9.4 \%)$.

\section{Risk factors for MRSA}

In total, 29 cases $(1.8 \%)$ were classified in the $\mathrm{MR}+$ group and 1625 in the $\mathrm{MR}$ - group. Univariate analysis found no significant difference between the proportion of female patients in the $\mathrm{MR}+$ group relative to all female patients ( 25 vs. 1464 ) and relative to all male patients ( 4 vs. 190$)(1.7 \%$ vs. $2.1 \%, p=0.567$; odds ratio [OR]: 0.808; $95 \%$ confidence interval [CI]: 0.275-3.229).

Similarly, as shown in Table 1 , no significant differences were found between age $\geq 80$ and $<80$ years, $\mathrm{BMI} \geq 30$ and $<30 \mathrm{~kg} / \mathrm{m}^{2}$, antibiotic use within 3 years or not, corticosteroid use or not, serum albumin $<3.5$ and $\geq 3.5 \mathrm{~g} / \mathrm{dL}, \mathrm{GFR}<50$ and $\geq 50 \mathrm{~mL} / \mathrm{min}$, presence or not of brain, thyroid, cardiac, or pulmonary disease, diabetes or asthma, smoking habit, or whether revision surgery was performed.

Multivariate analysis revealed no parameters as independent risk factors.

\section{Risk factors for S. aureus}

In total, 445 cases (26.9\%) were positive for S. aureus. Therefore, the number of patients in the SA + group was 445, with 1209 in the SA - group. From univariate analysis, the proportion of female patients in the SA + group relative to all female patients (411 vs. 1464) was significantly higher than relative to all male patients (34 vs. 190) $(28.1 \%$ vs. $17.9 \%, p=0.003$; OR: 1.790 ; $95 \%$ CI: 1.205-2.724). No significant difference was seen with any other parameters (Table 2).

According to multivariate analysis, only female sex ( $p=0.003$; OR: 1.790 ; $95 \%$ CI: $1.210-2.640)$ was an independent risk factor for the presence of $S$. aureus with a sensitivity of 0.924 , specificity of 0.129 .

\section{Calculation of costs}

The cost of each screening procedure was as follows: 28.7 yen to take nasal samples from all cases, 294.1 yen to isolate Staphylococcus strains from all samples, 200.4 yen to isolate $S$. aureus from Staphylococcus strains (91.1\% of all samples), 370.5 yen to divide $S$. aureus into MRSA and MSSA (26.9\% of all samples), and 77.8 yen to assess the culture results for all samples. Therefore, the total cost of screening, including personnel and material costs, was $28.7+294.1+200.4 \times 0.911+370.5 \times$ $0.269+77.8=682.9$ yen per person (Fig. 1). The cost of mupirocin ointment in Japan is 1641.3 yen for each $3-\mathrm{g}$ product. The cost for a medical assistant to spend 10 minutes instructing a patient on how to apply mupirocin ointment was 287.0 yen. Therefore, the total cost of decolonization was $1641.3+287.0=1928.3$ yen per person.

When using the UD strategy, all patients need decolonization but none need screening. Therefore, the cost of the UD strategy is 1928.3 yen per person.

For eradication of MRSA, because no risk factors for colonization were identified, it is impossible to select patients to undergo screening using the TS strategy. Mupirocin ointment was used as part of the US and TS strategies in patients who were MRSA-positive (29/1654 cases: $1.8 \%)$. Therefore, the average cost of both US and TS is $682.9+1928.3 \times 0.018=717.6$ yen per person (Fig. 2).

To eradicate $S$. aureus by the US strategy, all patients needed to be screened and treated by decolonization if S. aureus-positive (445/1654 cases: $26.9 \%)$. Therefore, the average cost of the US strategy was $682.9+1928.3 \times$ $0.269=1201.6$ yen per person. As for the TS strategy, screened cases were selected according to risk factors by the surgeon (77.8 yen). All female patients were screened (1464/1654 cases: $88.5 \%$ ) and treated by decolonization if $S$. aureus-positive (411/1654 cases: $24.8 \%)$. Therefore, the average cost of the TS strategy is $77.8+682.9 \times$ $0.885+1928.3 \times 0.248=1160.4$ yen per person $($ Fig. 3$)$.

\section{Incidence of SSI or PJI}

A total of 1522 cases (92.0\%) were observed for more than 2 years of follow-up. There were 6 cases of superficial SSI, all of which were primary THA cases. Pathogens were 1 case of MRSA, 1 of methicillin-resistant coagulase-negative Staphylococcus, 2 of MSSA, and 2 of methicillin-sensitive coagulase-negative Staphylococcus. Among these patients, SSI pathogens of 1 MSSA case and 1 methicillin-sensitive coagulase-negative Staphylococcus case were matched with nasal bacteria. None of these six SSI cases were MR + and only 1 case was SA+. There were no cases of deep incisional SSI. Other than these, there were no cases of PJI during the follow-up period.

\section{Discussion}

In this study, no risk factors for MRSA were identified and the risk factor for $S$. aureus carriage was female sex only. As for $S$. aureus carrier status, specificity of female sex as a risk factor was 0.129 . Because of low specificity, implementing the TS strategy considering this risk factor would require screening a considerable number of patients-amounting to $88.5 \%$ of all patients - with 4 of 29 (13.8\%) MRSA-positive cases and 34 of 445 (7.6\%) S. aureus-positive cases being overlooked. Thus, this parameter is not useful and no suitable risk factor for the TS strategy was identified. 
Table 1 Univariate analysis of MR+ and MR- groups

\begin{tabular}{|c|c|c|c|c|c|c|c|c|}
\hline \multirow{2}{*}{ Parameter } & & \multirow[b]{2}{*}{$\mathbf{n}$} & \multirow[b]{2}{*}{$M R+(n=29)$} & \multirow[b]{2}{*}{ MR- $(n=1625)$} & \multirow[b]{2}{*}{$P$-value } & \multirow[b]{2}{*}{ Odds ratio } & \multicolumn{2}{|c|}{ 95\% Confidence interva } \\
\hline & & & & & & & Lower & Upper \\
\hline \multirow[t]{2}{*}{ Sex } & Female & 1464 & $25(1.7 \%)$ & $1439(98.3 \%)$ & 0.567 & 0.808 & 0.275 & 3.229 \\
\hline & Male & 190 & $4(2.1 \%)$ & $186(97.9 \%)$ & & & & \\
\hline \multirow[t]{2}{*}{ Age (years) } & $\geq 80$ & 70 & $2(2.9 \%)$ & $68(97.1 \%)$ & 0.350 & 1.695 & 0.192 & 6.987 \\
\hline & $<80$ & 1584 & $27(1.7 \%)$ & $1557(98.3 \%)$ & & & & \\
\hline \multirow[t]{2}{*}{$\mathrm{BMI}\left(\mathrm{kg} / \mathrm{m}^{2}\right)$} & $\geq 30$ & 93 & $3(3.2 \%)$ & 90 (96.8\%) & 0.221 & 1.967 & 0.374 & 6.605 \\
\hline & $<30$ & 1561 & $26(1.7 \%)$ & $1535(98.3 \%)$ & & & & \\
\hline \multirow[t]{2}{*}{ Antibiotic use within 3 years } & + & 337 & $8(2.4 \%)$ & $329(97.6 \%)$ & 0.351 & 1.500 & 0.569 & 3.565 \\
\hline & - & 1317 & $21(1.6 \%)$ & 1296 (98.4\%) & & & & \\
\hline \multirow[t]{2}{*}{ Corticosteroid use } & + & 36 & $2(5.6 \%)$ & $34(94.4 \%)$ & 0.130 & 3.461 & 0.384 & 14.752 \\
\hline & - & 1618 & $27(1.7 \%)$ & 1591 (98.3\%) & & & & \\
\hline \multirow[t]{2}{*}{ Albumin (g/dL) } & $<3.5$ & 18 & $1(5.6 \%)$ & 17 (94.4\%) & 0.274 & 3.374 & 0.078 & 23.091 \\
\hline & $\geq 3.5$ & 1636 & $28(1.7 \%)$ & 1608 (98.3 \%) & & & & \\
\hline \multirow[t]{2}{*}{ GFR (mL/min) } & $<50$ & 108 & $3(2.8 \%)$ & $105(97.2 \%)$ & 0.432 & 1.670 & 0.318 & 5.586 \\
\hline & $\geq 50$ & 1546 & $26(1.7 \%)$ & $1520(98.3 \%)$ & & & & \\
\hline \multirow[t]{2}{*}{ Brain disease } & + & 54 & $0(0.0 \%)$ & $54(100.0 \%)$ & 1.000 & 0.000 & 0.000 & 4.078 \\
\hline & - & 1600 & $29(1.8 \%)$ & 1571 (98.2\%) & & & & \\
\hline \multirow[t]{2}{*}{ Thyroid disease } & + & 29 & $1(3.4 \%)$ & $28(96.6 \%)$ & 0.404 & 2.036 & 0.048 & 13.262 \\
\hline & - & 1625 & $28(1.7 \%)$ & 1597 (98.3\%) & & & & \\
\hline \multirow[t]{2}{*}{ Cardiac disease } & + & 21 & $0(0.0 \%)$ & $21(100.0 \%)$ & 1.000 & 0.000 & 0.000 & 11.254 \\
\hline & - & 1633 & $29(1.8 \%)$ & 1604 (98.2\%) & & & & \\
\hline \multirow[t]{2}{*}{ Pulmonary disease } & + & 20 & $0(0.0 \%)$ & $20(100.0 \%)$ & 1.000 & 0.000 & 0.000 & 11.873 \\
\hline & - & 1634 & $29(1.8 \%)$ & 1605 (98.2\%) & & & & \\
\hline \multirow[t]{2}{*}{ Diabetes } & + & 109 & $1(0.9 \%)$ & $108(99.1 \%)$ & 1.000 & 0.502 & 0.012 & 3.097 \\
\hline & - & 1545 & $28(1.8 \%)$ & 1517 (98.2\%) & & & & \\
\hline \multirow[t]{2}{*}{ Asthma } & + & 55 & $2(3.6 \%)$ & 53 (96.4\%) & 0.251 & 2.196 & 0.247 & 9.130 \\
\hline & - & 1599 & 27 (1.7\%) & 1572 (98.3\%) & & & & \\
\hline \multirow[t]{2}{*}{ Smoking } & + & 76 & $1(1.3 \%)$ & 75 (98.7\%) & 1.000 & 0.738 & 0.018 & 4.594 \\
\hline & - & 1578 & $28(1.8 \%)$ & 1550 (98.2\%) & & & & \\
\hline \multirow[t]{2}{*}{ Revision surgery } & + & 155 & $2(1.3 \%)$ & $153(98.7 \%)$ & 1.000 & 0.713 & 0.081 & 2.883 \\
\hline & - & 1499 & 27 (1.8\%) & 1472 (98.2\%) & & & & \\
\hline
\end{tabular}

BMI Body mass index, GFR Glomerular filtration rate. ${ }^{*} P<0.05$ Values are shown as the number of patients (\%). Fisher's exact test

Previous studies have attempted to clarify various risk factors, including male sex, white race, obesity, asthma [12], diabetes [13], and renal disease [14] for both MSSA and MRSA colonization, but opinions remain divided. While smoking was described as a risk factor in one study [15], it was found to have no relationship with $S$. aureus colonization in other studies $[1,12]$. De Wouters et al. reported that although Belgian guidelines recommend TS for MRSA carriage on admission for high-risk populations only (age $>80$ years; inpatient admission in the previous 6 months; past history of MRSA colonization; living in a nursing or residential home; exposure to invasive devices; chronic wounds or skin lesions; working in health care; and being in contact with farm animals), there was no correlation between identified MRSA carriers and these risk factors [16]. No risk factors for MRSA were identified in this study. Moreover, when female sex was applied as a risk factor for TS, the average cost of US vs. TS per person to decolonize S. aureus-positive cases was 1201.6 vs. 1160.4 yen; thus, TS could reduce costs by 41.2 yen $(3.6 \%)$ compared with US. As such, no useful predictive factors that enable the successful implementation of TS were identified and the strategy was also not that costeffective.

The UD strategy is advocated in clinical units with a high risk of MRSA infection, such as intensive care units and emergency units, because it can protect patients 
Table 2 Univariate analysis of SA+ and SA-groups

\begin{tabular}{|c|c|c|c|c|c|c|c|c|}
\hline \multirow{2}{*}{ Parameter } & & \multirow[b]{2}{*}{$\mathbf{n}$} & \multirow[b]{2}{*}{$S A+(n=445)$} & \multirow[b]{2}{*}{ SA- $(n=1209)$} & \multirow[b]{2}{*}{$P$-value } & \multirow[b]{2}{*}{ Odds ratio } & \multicolumn{2}{|c|}{ 95\% Confidence interva } \\
\hline & & & & & & & Lower & Upper \\
\hline \multirow[t]{2}{*}{ Sex } & Female & 1464 & $411(28.1 \%)$ & $1053(71.9 \%)$ & $0.003 *$ & 1.790 & 1.205 & 2.724 \\
\hline & Male & 190 & $34(17.9 \%)$ & $156(82.1 \%)$ & & & & \\
\hline \multirow[t]{2}{*}{ Age (years) } & $\geq 80$ & 70 & $18(25.7 \%)$ & $52(74.3 \%)$ & 0.891 & 0.938 & 0.510 & 1.652 \\
\hline & $<80$ & 1584 & $427(27.0 \%)$ & $1157(73.0 \%)$ & & & & \\
\hline \multirow[t]{2}{*}{$\mathrm{BMI}\left(\mathrm{kg} / \mathrm{m}^{2}\right)$} & $\geq 30$ & 93 & $29(31.2 \%)$ & $64(68.8 \%)$ & 0.337 & 1.247 & 0.764 & 1.994 \\
\hline & $<30$ & 1561 & $416(26.6 \%)$ & $1145(73.4 \%)$ & & & & \\
\hline \multirow[t]{2}{*}{ Antibiotic use within 3 years } & + & 337 & $84(24.9 \%)$ & $253(75.1 \%)$ & 0.372 & 0.879 & 0.659 & 1.165 \\
\hline & - & 1317 & $361(27.4 \%)$ & $956(72.6 \%)$ & & & & \\
\hline \multirow[t]{2}{*}{ Corticosteroid use } & + & 36 & $10(27.8 \%)$ & $26(72.2 \%)$ & 0.852 & 1.046 & 0.446 & 2.264 \\
\hline & - & 1618 & 435 (26.9\%) & $1183(73.1 \%)$ & & & & \\
\hline \multirow[t]{2}{*}{ Albumin (g/dL) } & $<3.5$ & 18 & $6(33.3 \%)$ & $12(66.7 \%)$ & 0.593 & 1.363 & 0.417 & 3.953 \\
\hline & $\geq 3.5$ & 1636 & $439(26.8 \%)$ & 1197 (73.2 \%) & & & & \\
\hline \multirow[t]{2}{*}{ GFR (mL/min) } & $<50$ & 108 & $30(27.8 \%)$ & $78(72.2 \%)$ & 0.823 & 1.048 & 0.654 & 1.643 \\
\hline & $\geq 50$ & 1546 & $415(26.8 \%)$ & $1131(73.2 \%)$ & & & & \\
\hline \multirow[t]{2}{*}{ Brain disease } & + & 54 & $9(16.7 \%)$ & $45(83.3 \%)$ & 0.088 & 0.534 & 0.228 & 1.118 \\
\hline & - & 1600 & $436(27.3 \%)$ & $1164(72.7 \%)$ & & & & \\
\hline \multirow[t]{2}{*}{ Thyroid disease } & + & 29 & 11 (37.9\%) & $18(62.1 \%)$ & 0.204 & 1.676 & 0.709 & 3.783 \\
\hline & - & 1625 & $434(26.7 \%)$ & 1191 (73.3\%) & & & & \\
\hline \multirow[t]{2}{*}{ Cardiac disease } & + & 21 & $9(42.9 \%)$ & $12(57.1 \%)$ & 0.133 & 2.058 & 0.760 & 5.364 \\
\hline & - & 1633 & $436(26.7 \%)$ & 1197 (73.3\%) & & & & \\
\hline \multirow[t]{2}{*}{ Pulmonary disease } & + & 20 & $5(25.0 \%)$ & $15(75.0 \%)$ & 1.000 & 0.905 & 0.256 & 2.638 \\
\hline & - & 1634 & $440(26.9 \%)$ & $1194(73.1 \%)$ & & & & \\
\hline \multirow[t]{2}{*}{ Diabetes } & + & 109 & $32(29.4 \%)$ & 77 (70.6\%) & 0.576 & 1.139 & 0.718 & 1.771 \\
\hline & - & 1545 & $413(26.7 \%)$ & $1132(73.3 \%)$ & & & & \\
\hline \multirow[t]{2}{*}{ Asthma } & + & 55 & 17 (30.9\%) & 38 (69.1\%) & 0.536 & 1.224 & 0.641 & 2.249 \\
\hline & - & 1599 & $428(26.8 \%)$ & 1171 (73.2\%) & & & & \\
\hline \multirow[t]{2}{*}{ Smoking } & + & 76 & $16(21.1 \%)$ & 60 (78.9\%) & 0.289 & 0.714 & 0.380 & 1.273 \\
\hline & - & 1578 & 429 (27.2\%) & 1149 (72.8\%) & & & & \\
\hline \multirow[t]{2}{*}{ Revision surgery } & + & 155 & $32(20.6 \%)$ & $123(79.4 \%)$ & 0.071 & 0.684 & 0.441 & 1.036 \\
\hline & - & 1499 & $413(27.6 \%)$ & 1086 (72.4\%) & & & & \\
\hline
\end{tabular}

BMI Body mass index, GFR Glomerular filtration rate. ${ }^{*} P<0.05$ Values are shown as the number of patients (\%). Fisher's exact test.

during a period of vulnerability to infection and it can prevent delayed decolonization pending the results of screening [7]. However, in cases of elective surgery like arthroplasty, there is no urgency that requires UD, because patients are not particularly vulnerable and the waiting period for screening results is irrelevant. Moreover, UD as empiric therapy is not recommended because of the risk of increasing bacterial resistance [11]. Prior mupirocin use was reported to increase the risk of mupirocin resistance in MRSA carriers by 9 fold [17]. According to Graber and Schwartz, failure of decolonization may be the result of increased mupirocin resistance [18]. Another disadvantage of UD is financial burden. In this study, mupirocin ointment at 1928.3 yen/product is needed to implement UD for all patients when including personnel costs. In the United States, Stirton et al. reported the cost of empiric treatment with mupirocin for all patients as an estimated $\$ 24.65$ per patient (equivalent to 2711.5 yen at 110 yen to 1 US Dollar), which included the personnel costs for instruction on mupirocin application [19].

The incidence of deep SSI in THA was reported as $1.1 \%$ [20], and the prevalence of revision THA due to PJI was reported as $0.4 \%$ following primary procedures and $1.6 \%$ following revision hip arthroplasty [21]. Bozic and Ries reported a longer duration of hospitalization with revision arthroplasty for infection than with aseptic loosening ( 28.2 vs. 8.1 days, $p<0.001)$ as well as higher 


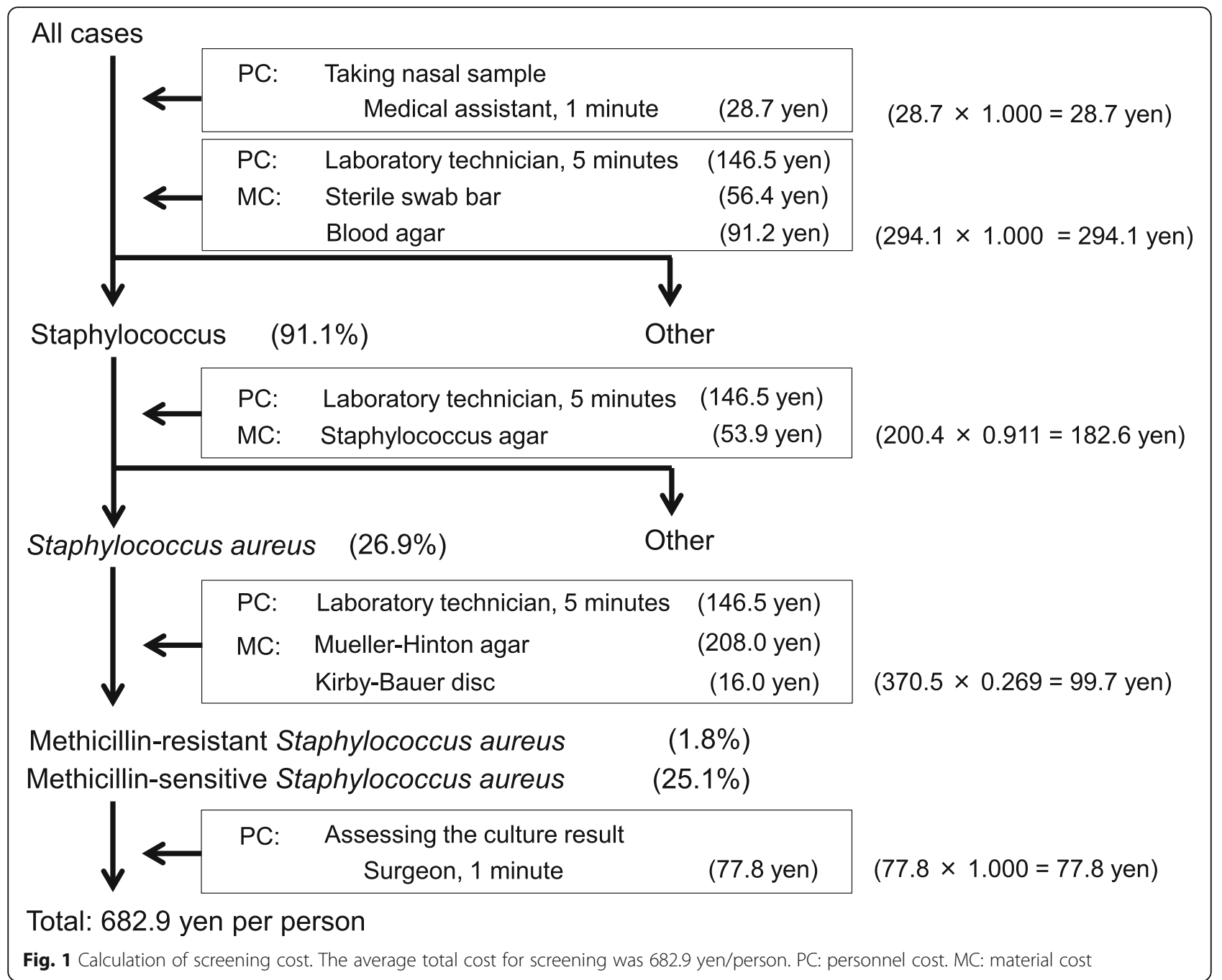

total hospital cost $(\$ 96,166$ vs. $\$ 34,866, p<0.001)$ and higher outpatient charges $(\$ 48,348$ vs. $\$ 16,411, p<$ 0.001) [22]. The cost of care for treatment of deep SSI caused by methicillin-resistant strains was estimated at $\$ 107,264$ compared with $\$ 68,053$ when caused by sensitive strains [2]. Therefore, revision arthroplasty due to infection is very costly.

Regarding SSI after total joint arthroplasty, MRSA and MSSA were reported as the most common pathogens [23]. Colonization of the nares occurs at higher rates compared with other body surfaces, and $65 \%$ of cases of MRSA colonization were detected in the nares [24]. There are three general sources of infection: endogenous, exogenous, and hematogenous [25]. Nasal carriage of $S$. aureus is thought to be endogenous to patients and is a well-established risk factor for SSI or PJI. The risk of SSI following orthopedic surgery was reported as 6.9 times higher among patients with preoperative MRSA nasal colonization [26] and 2.8 times higher with preoperative MSSA nasal colonization [27]. Thus, because nasal carriage of $S$. aureus is an important factor for infection, the importance of intranasal decolonization cannot be overemphasized. Mupirocin can eliminate $S$. aureus nasal carriage in healthy persons for up to 3 months, with a corresponding effect on hand carriage [28]. Treating nasal carriage usually leads to eliminating $S$. aureus, including MRSA, from other areas of the body [29].

The effectiveness of US for reducing SSI following THA has been widely reported. According to Nixon et al., implementing the US strategy for MRSA eradication reduced the cost of care, considering the enormous costs incurred by revision arthroplasty and prolonged admission due to infection [9]. Hacek et al. implemented US for 1495 cases of total joint arthroplasty with decolonization for $S$. aureus-positive patients and reported reduced SSI compared with 583 non-screened or decolonized control cases $(0.77 \%$ vs. $1.7 \%, p \leq 0.1)$ [4]. Pofahl et al. reported that the SSI rate of US with decolonization for MRSA-positive patients was significantly lower than that for non-intervention controls $(0 \%$ 


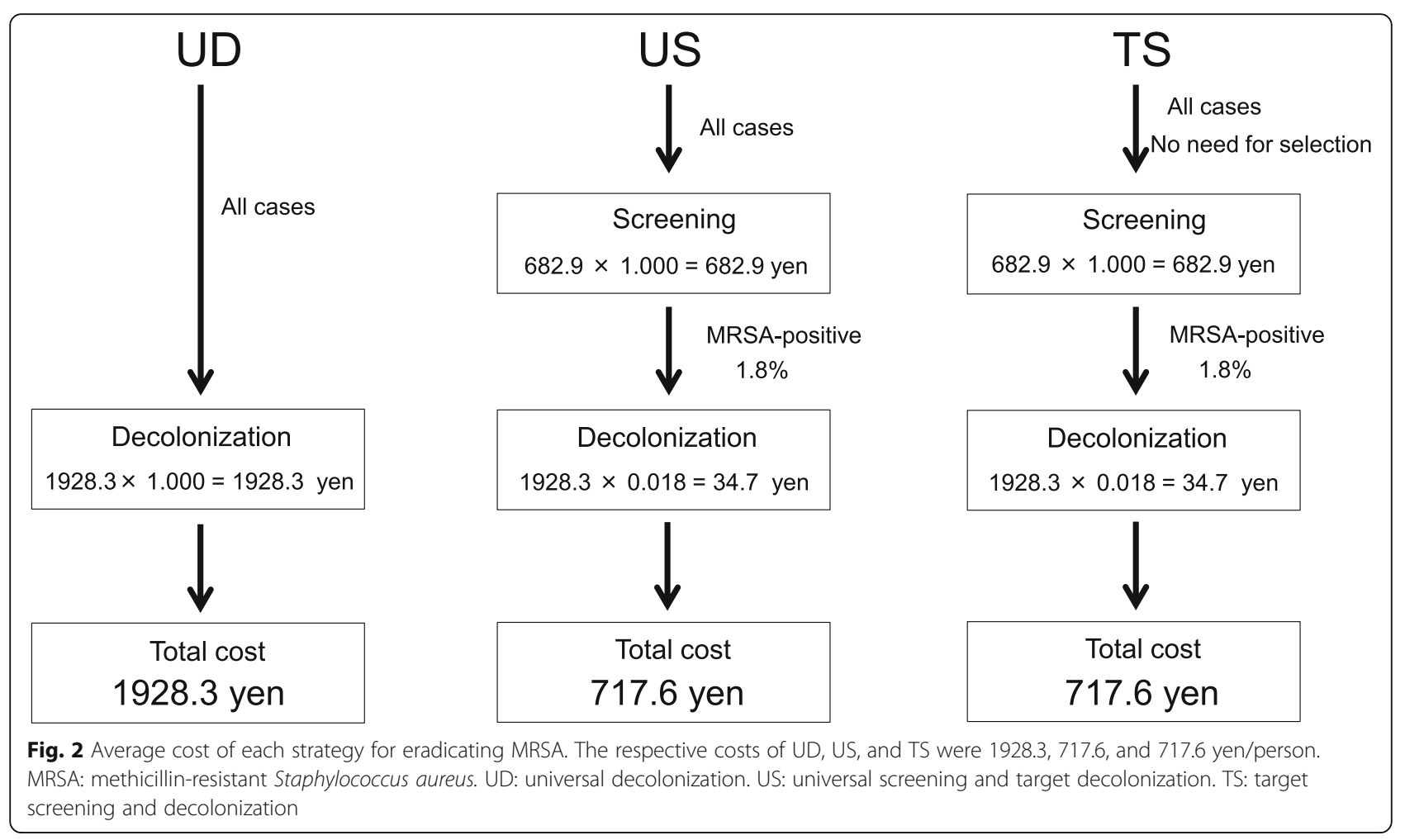

vs. $0.30 \%, p=0.04$ ) for total joint arthroplasty [5]. Thus, implementing US can reduce the SSI rate, costs related to revision arthroplasty, and hospitalization duration.

In the present study, there were 6 cases of superficial SSI but no cases of deep incisional SSI or PJI. Among the six superficial SSI cases, 1 was SA+, 5 were SA-, and none were MR+. Although the number of SSIs was overall very low, considering the SA + rate of $26.9 \%$ and SA - rate of $73.1 \%$, the number of SSIs in the SA + group can be considered very low despite the different risk factors. We decolonize only MRSA-positive patients with mupirocin and treat both nares twice daily for 5 days. At present, we believe that this method is adequate because of the low SSI rate in the MR + and SA + groups in this study. However, several reports recommend decolonization in patients who are $S$. aureus-positive $[4,28]$ but whether this should be done remains controversial. Further research would be needed to identify patients in whom decolonization should be performed.

In this study, no risk factors were identified for MRSA carriers and only female sex was identified, albeit with low specificity, for S. aureus carriers. Thus, no risk factors that could help with TS were identified. Also, TS was determined not to be as cost-effective as US. UD, which is suitable for intensive care units and emergency rooms, is a more expensive strategy than US for eradicating both MRSA and S. aureus. US would be a more cost-effective strategy than UD for THA patients whose screening results can be waited for. Therefore, overall,
US is considered to be the most cost-effective strategy with reduced sampling error rates for THA patients.

There are several limitations in this study. First, the study population included few patients with extremely high risk such as age $>90$ years, poorly controlled diabetes, currently undergoing dialysis, and those with human immunodeficiency virus infection. Second, the study had a retrospective design, which means that there was no information available on whether there was a recent history of parenteral antibiotic therapy [30], homosexual activity [31], a recent stay in a nursing home or emergency ward, living with a health care worker, or being a health care worker [32], all of which are putative risk factors for nasal carriage. Third, we attempted to identify risk factors for nasal bacterial carriage in a Japanese population, but different results might be obtained elsewhere. Further investigation is needed to clarify the risk factors for other countries. Fourth, in the calculation of costs, personnel costs would differ considerably depending on the methods used and the insurance systems in place in each country. Fifth, we relied on a nasal culture swab method for determining the presence of MRSA and S. aureus; however, this method has low sensitivity and might introduce false-negative results [6]. For high-risk populations, it is desirable to use more reliable methods, such as polymerase chain reaction, despite their higher cost. Sixth, in order to determine which strategy is the most appropriate, ideally there should have been three intervention cohorts (UD, US, and TS) 


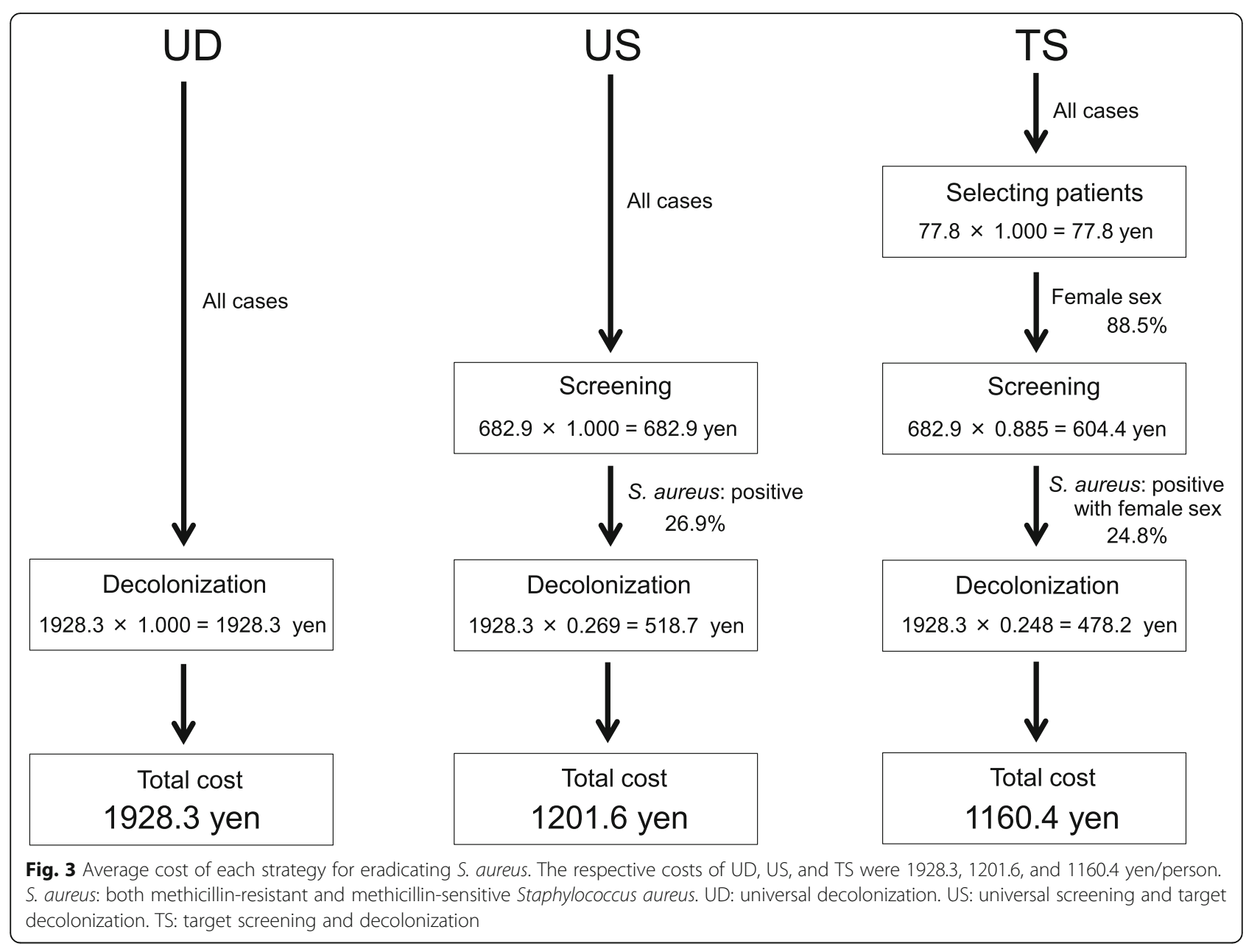

and a non-intervention cohort (without decolonization). However, there was no UD, TS, or non-intervention cohort in this retrospective study, so we could not provide any comparative data on the incidence of SSI or PJI in these groups. Seventh, although some researchers have emphasized the effectiveness of a bundle protocol consisting of self-administered nasal mupirocin and bathing with chlorhexidine gluconate [33, 34], others have used only nasal mupirocin ointment $[4,6]$. In this study, we simulated nasal decolonization alone. Moreover, although the nose is considered to be the most important carriage site $[28,29]$, further investigation is needed to determine whether it is necessary to obtain screening swabs from other body sites. Finally, there were only 6 cases of superficial SSI, 4 of which the causative pathogens did not match the nasal bacteria, and there were no cases of PJI in the 2-year follow-up period. Therefore, from the results of this study, it is unclear whether bacteria in the nose affect SSI or PJI. Further investigation is needed to clarify the relationship between nasal bacterial carriage and infection in THA.

\section{Conclusions}

No predictive factors for nasal carriage of MRSA and $S$. aureus, which are useful for implementing the TS strategy, were identified. TS reduced the cost of eradicating S. aureus by only $3.6 \%$ compared with US. The cost of UD for eradicating both MRSA and $S$. aureus is greater than that of US or TS. Taking these findings together, the US strategy is considered to reduce sampling errors and to be the most cost-effective strategy to implement in THA patients.

\footnotetext{
Abbreviations

THA: Total hip arthroplasty; PJI: Periprosthetic joint infection; MRSA: Methicillin-resistant Staphylococcus aureus; MSSA: MethicillinsensitiveStaphylococcus aureus; S. aureus: Both MRSA and MSSA; SSI: Surgical site infection; UD: Universal decolonization; US: Universal screening and target decolonization; TS: Target screening and decolonization; BMI: Body mass index; GFR: Glomerular filtration rate; OR: Odds ratio; Cl: Confidence interval
}

Acknowledgements

Not applicable. 


\section{Authors' contributions}

HT conceived and designed the study and drafted the manuscript; HS analyzed the data and interpreted the results; AA, KY, RS acquired the data; MS interpreted the results. All authors have read and approved the final manuscript.

\section{Funding}

The authors state that this work has not received financial support.

\section{Availability of data and materials}

The datasets used and/or analyzed during the current study are available from the corresponding author on reasonable request.

\section{Ethics approval and consent to participate}

The institutional review board of Kanagawa Rehabilitation Hospital approved the study protocol (krh-2020-2). This study was retrospective research study, and the requirement for informed consent was waived.

\section{Consent for publication}

Not applicable.

\section{Competing interests}

The authors declare that they have no competing interests.

Received: 15 June 2020 Accepted: 24 January 2021

Published online: 01 February 2021

\section{References}

1. Walsh AL, Fields AC, Dieterich JD, Chen DD, Bronson MJ, Moucha CS. Risk factors for staphylococcus aureus nasal colonization in joint arthroplasty patients. J Arthroplasty. 2018;33(5):1530-3.

2. Parvizi J, Pawasarat IM, Azzam KA, Joshi A, Hansen EN, Bozic KJ. Periprosthetic joint infection: the economic impact of methicillin-resistant infections. J Arthroplasty. 2010;25(6 Suppl):103-7.

3. Gao Z, Du Y, Piao S, Sun J, Li X, Zhou Y. Comparison between the staphylococci aureus and coagulase-negative staphylococci infected total joint arthroplasty treated by two-stage revision: A retrospective study with two year minimum follow-up. J Orthop Sci. 2019;24(1):109-15.

4. Hacek DM, Robb WJ, Paule SM, Kudrna JC, Stamos VP, Peterson LR. Staphylococcus aureus nasal decolonization in joint replacement surgery reduces infection. Clin Orthop Relat Res. 2008:466(6):1349-55.

5. Pofahl WE, Goettler CE, Ramsey KM, Cochran MK, Nobles DL, Rotondo MF. Active surveillance screening of MRSA and eradication of the carrier state decreases surgical-site infections caused by MRSA. J Am Coll Surg. 2009;208: 981-6.

6. Courville XF, Tomek IM, Kirkland KB, Birhle M, Kantor SR, Finlayson SR. Costeffectiveness of preoperative nasal mupirocin treatment in preventing surgical site infection in patients undergoing total hip and knee arthroplasty: a cost-effectiveness analysis. Infect Control Hosp Epidemiol. 2012;33(2):152-9.

7. Huang SS, Septimus E, Kleinman K, Moody J, Hickok J, Avery TR, Lankiewicz J, Gombosev A, Terpstra L, Hartford F, Hayden MK, Jernigan JA, Weinstein RA, Fraser VJ, Haffenreffer K, Cui E, Kaganov RE, Lolans K, Perlin JB, Platt R, CDC Prevention Epicenters Program; AHRQ DECIDE Network and Healthcare-Associated Infections Program. . Targeted versus universal decolonization to prevent ICU infection. N Engl J Med. 2013;368(24):225565.

8. Dave J, Jenkins PJ, Hardie A, Smith M, Gaston P, Gibb AP, Templeton K, Simpson AH. A selected screening programme was less effective in the detection of methicillin-resistant Staphylococcus Aureus colonisation in an orthopaedic unit. Int Orthop. 2014;38(1):163-7.

9. Nixon M, Jackson B, Varghese P, Jenkins D, Taylor G. Methicillin-resistant Staphylococcus aureus on orthopaedic wards: incidence, spread, mortality, cost and control. J Bone Joint Surg Br. 2006;88:812-7.

10. Coia JE, Duckworth GJ, Edwards DI, FarringtonM, Fry C, Humphreys H, Mallaghan C, Tucker DR, Joint Working Party of the British Society of Antimicrobial Chemotherapy, Hospital Infection Society, Infection Control Nurses Association. Guidelines for the Control and Prevention of MeticillinResistant Staphylococcus Aureus (MRSA) in Healthcare Facilities. J Hosp Infect. 2006;63(Suppl 1):1-44.
11. Chen AF, Charles B, Wessel NR. Staphylococcus Aureus screening and decolonization in orthopaedic surgery and reduction of surgical site infections. Clin Orthop Relat Res. 2013;471(7):2383-99.

12. Campbell KA, Cunningham C, Hasan S, Hutzler L, Bosco JA 3rd. Risk factors for developing staphylococcus aureus nasal colonization in spine and arthroplasty surgery. Bull Hosp Jt Dis. 2015;73(4):276-81.

13. Lowy FD. Staphylococcus aureus infections. N Engl J Med. 1998;339(8):52032.

14. Price MF, Carlini M, Houston S, Gentry LO. Prevalence of nasal colonization with methicillin-resistant Staphylococcus aureus in selected patient populations. Infect Control Hosp Epidemiol. 2000;21(9):603-5.

15. Choi CS, Yin CS, Bakar AA, Sakewi Z, Naing NN, Jamal F, Othman N. Nasal carriage of Staphylococcus aureus among healthy adults. J Microbiol Immunol Infect. 2006;39(6):458-64.

16. de Wouters S, Daxhelet J, Kaminski L, Thienpont E, Cornu O, Yombi JC. Selective methicillin-resistant Staphylococcus Aureus (MRSA) screening of a high risk population does not adequately detect MRSA carriers within a country with low MRSA prevalence. Acta Orthop Belg. 2015;81(4):620-8.

17. Caffrey AR, Quilliam BJ, LaPlante KL. Risk factors associated with mupirocin resistance in meticillin-resistant Staphylococcus aureus. J Hosp Infect. 2010; 76(3):206-10.

18. Graber CJ, Schwartz BS. Failure of decolonization in patients with infections due to mupirocin-resistant strains of community-associated methicillinresistant Staphylococcus Aureus. Infect Control Hosp Epidemiol. 2008;29(3): 284.

19. Stirton J, Herron JS, Nandi S. Empiric treatment is less costly than Staphylococcus aureus screening and decolonization in total joint arthroplasty patients. Arthroplast Today. 2017;4(3):323-4.

20. Phillips CB, Barrett JA, Losina E, Mahomed NN, Lingard EA, Guadagnoli E, Baron JA, Harris WH, Poss R, Katz JN. Incidence rates of dislocation, pulmonary embolism, and deep infection during the first six months after elective total hip replacement. J Bone Joint Surg Am. 2003:85-A(1):20-6.

21. Lenguerrand E, Whitehouse MR, Beswick AD, Jones SA, Porter ML, Blom AW. Revision for prosthetic joint infection following hip arthroplasty: Evidence from the National Joint Registry. Bone Joint Res. 2017:6(6):391-8.

22. Bozic KJ, Ries MD. The impact of infection after total hip arthroplasty on hospital and surgeon resource utilization. J Bone Joint Surg Am. 2005;87(8): 1746-51.

23. Berríos-Torres SI, Yi SH, Bratzler DW, Ma A, Mu Y, Zhu L, Jernigan JA. Activity of commonly used antimicrobial prophylaxis regimens against pathogens causing coronary artery bypass graft and arthroplasty surgical site infections in the United States, 2006-2009. Infect Control Hosp Epidemiol. 2014;35(3): 231-9.

24. Samad A, Banerjee D, Carbarns N, Ghosh S. Prevalence of methicillinresistant Staphylococcus aureus colonization in surgical patients, on admission to a Welsh hospital. J Hosp Infect. 2002;51(1):43-6.

25. Weiser MC, Moucha CS. The current state of screening and decolonization for the prevention of Staphylococcus aureus surgical site infection after total hip and knee arthroplasty. J Bone Joint Surg Am. 2015:97(17):1449-58.

26. Kim DH, Spencer M, Davidson SM, Li L, Shaw JD, Gulczynski D, Hunter DJ, Martha JF, Miley GB, Parazin SJ, Dejoie P, Richmond JC. Institutional prescreening for detection and eradication of methicillin-resistant Staphylococcus aureus in patients undergoing elective orthopaedic surgery. J Bone Joint Surg Am. 2010;92(9):1820-6.

27. Berthelot P, Grattard F, Cazorla C, Passot JP, Fayard JP, Meley R, Bejuy J, Farizon F, Pozzetto B, Lucht F. Is nasal carriage of Staphylococcus aureus the main acquisition pathway for surgical-site infection in orthopaedic surgery? Eur J Clin Microbiol Infect Dis. 2010;29(4):373-82.

28. Reagan DR, Doebbeling BN, Pfaller MA, Sheetz CT, Houston AK, Hollis RJ, Wenzel RP. Elimination of coincident Staphylococcus aureus nasal and hand carriage with intranasal application of mupirocin calcium ointment. Ann Intern Med. 1991:114(2):101-6.

29. von Eiff C, Becker K, Machka K, Stammer H, Peters G. Nasal carriage as a source of Staphylococcus Aureus Bacteremia.\&nbsp;Study group. . N Engl J Med. 2001;344(1):11-6

30. Al-Rawahi GN, Reynolds S, Porter SD, Forrester L, Kishi L, Chong T, Bowie WR, Doyle PW. Community-associated CMRSA-10 (USA-300) is the predominant strain among methicillin-resistant Staphylococcus aureus strains causing skin and soft tissue infections in patients presenting to the emergency department of a Canadian tertiary care hospital. J Emerg Med. 2010;38(1):6-11. 
31. Kotpal R, Bhalla SKP, Dewan P, Kaur RR. Incidence and Risk Factors of Nasal Carriage of Staphylococcus aureus in HIV-Infected Individuals in Comparison to HIV-Uninfected Individuals: A Case-Control Study. J Int Assoc Provid AIDS Care. 2016;15(2):141-7.

32. Ahmadi E, Khojasteh M, Mortazavi SM, Khan-Mohammadi F, Kazemnia A, Beheshtipour J, Raeeszadeh M. Prevalence of and risk factors for methicillinresistant Staphylococcus aureus nasal carriage in the West of Iran: a population-based cross-sectional study. BMC Infect Dis. 2019;19(1):899.

33. Kline SE, Neaton JD, Lynfield R, Ferrieri P, Kulasingam S, Dittes K, Glennen A, Jawahir S, Kaizer A, Menk J, Johnson JR. Randomized controlled trial of a self-administered five-day antiseptic bundle versus usual disinfectant soap showers for preoperative eradication of Staphylococcus aureus colonization. Infect Control Hosp Epidemiol. 2018;39(9):1049-57.

34. Sporer SM, Rogers T, Abella L. Methicillin-resistant and methicillin-sensitive Staphylococcus aureus screening and decolonization to reduce surgical site infection in elective total joint arthroplasty. J Arthroplasty. 2016;31(9 Suppl): $144-7$.

\section{Publisher's Note}

Springer Nature remains neutral with regard to jurisdictional claims in published maps and institutional affiliations.

Ready to submit your research? Choose BMC and benefit from:

- fast, convenient online submission

- thorough peer review by experienced researchers in your field

- rapid publication on acceptance

- support for research data, including large and complex data types

- gold Open Access which fosters wider collaboration and increased citations

- maximum visibility for your research: over $100 \mathrm{M}$ website views per year

At $\mathrm{BMC}$, research is always in progress.

Learn more biomedcentral.com/submissions 